\title{
Relationship Between The Number of Reasons Students Cited To Study En- gineering and Their Retention and Graduation Rates
}

\section{Mr. Paa Kwasi Adusei, University of Cincinnati}

I am a PhD student with the Materials Science and Engineering department at the University of Cincinnati that has a passion for engineering education. I work as a graduate and research assistant with the Engineering Education department. My interests in Engineering education is specifically in student motivation and learning theories.

\section{Dr. Nora Honken, University of Cincinnati}

Nora is an Assistant Professor in the Engineering Education Department at The University of Cincinnati. She holds a PhD in Educational Leadership and Organizational Development for the University of Louisville, a MS in Industrial Engineering from Arizona State University and a BS in Industrial Engineering from Virginia Tech. She also has extensive industrial experience.

\section{Dr. Patricia A. Ralston, University of Louisville}

Dr. Patricia A. S. Ralston is Professor and Chair of the Department of Engineering Fundamentals at the University of Louisville. She received her B.S., MEng, and $\mathrm{PhD}$ degrees in chemical engineering from the University of Louisville. Dr. Ralston teaches undergraduate engineering mathematics and is currently involved in educational research on the effective use of technology in engineering education, the incorporation of critical thinking in undergraduate engineering education, and retention of engineering students. She leads a research group whose goal is to foster active interdisciplinary research which investigates learning and motivation and whose findings will inform the development of evidence-based interventions to promote retention and student success in engineering. Her fields of technical expertise include process modeling, simulation, and process control. 


\title{
Relationship Between the Number of Reasons Students Cited to Study Engineering and Their Retention and Graduation Rates
}

\begin{abstract}
This paper is a completed research paper that looks at the correlation between number of reasons stated by students for pursuing engineering and their associated retention rates. Many theories have been studied with relation to college student retention for the general college student population as well as within engineering. This study, framed in two such theories, Social Cognitive Theory and Expectancy Value Theory, investigated the number of reasons students cited to pursue an engineering degree and their likelihood of being retained. Survey data from first year students from a large metropolitan research university in the 2010, 2011 and 2012 cohorts were used. Results from $t$-test showed that in two of the cohorts the students who were retained in engineering the first year had significantly more reasons for choosing engineering. When combining all three cohorts, results from logistic regression showed for each reason cited students were between $7 \%$ and $28 \%$ (based on $95 \%$ confidence intervals) more likely to be retained after one year, and between $12 \%$ and $32 \%$ more likely to be retained after three years.
\end{abstract}

\section{Introduction}

There has been increased attention in the public domain to college retention and graduation rates which have been influenced by multiple factors such as the increasing number of states using retention and graduation rates in funding formulas for colleges ${ }^{1,2}$ the publication of retention and graduation rates ${ }^{3}$ and the amount of student loan debt ${ }^{3-5}$. The attention paid to retention in engineering programs has also increased, fueled by the overall movement to increase graduation rates and additionally the call for more engineering graduates ${ }^{6}$. This is particularly interesting due to the debate in recent times on the future lack of qualified candidates to fill STEM positions ${ }^{6,7}$.

There has therefore been a necessity to increase the number of students in STEM programs and understand what attracts students into these disciplines and what keeps them engaged in these disciplines. Several papers have been presented on student retention looking at it from various points of view ${ }^{8-12}$ there have also been studies on motivating factors for choosing engineering ${ }^{8,13}$. The current study seeks to determine if there is a correlation between these two. Specifically, this study investigates the number of reasons students cited for choosing to study engineering and their retention in engineering.

\section{Background Literature}

There are many theories as to why students choose a career or educational path. For this study two main theories stand out: Social Cognitive Theory and Expectancy Value Theory.

\section{Social Cognitive Theory}

The Social Cognitive Theory (SCT) is a relatively new theory that sheds light on how basic academic and career interests develop, how educational and career choices are made, and 
how academic and career success is obtained. The basic building blocks of this theory are selfefficacy beliefs, outcome expectations, goals or intrinsic values and interests ${ }^{14-16}$.

Self-efficacy belief generally describes an individual's personal beliefs about his or her ability and capability to perform an action. They are dynamic and vary from task to task. It is derived from personal performance accomplishments, vicarious experiences, social persuasion, and emotional/physiological states one experiences whilst engaged in a task. ${ }^{14-16}$.

Outcome expectation refers to beliefs about the results or outcome of performing a task. People are more likely to engage in tasks where they foresee their involvement leading to valued, positive outcomes. Intrinsic values and interests as well as personal goals describe the enjoyment associated with an activity. People tend to do what they enjoy ${ }^{14-16}$.

Social supports and barriers are also an important component of this theory and affects how educational and career choices are made. Reasons that are within the realm of social support influence such as the influence of parents, school counselor or someone else a student knows ${ }^{14}$.

\section{Expectancy-Value Theory}

The Expectancy-Value Theory describes behavior as a function of the expectancies one has for being successful and the value placed on the goal towards which one is working ${ }^{17}$. It is heavily linked to motivation since if one has a high competence belief (expectancy of doing well) and sees value in what he/she is doing, he/she will be more motivated to pursue it. As opposed to one who has a low competency belief and/or sees little value in pursuing an activity. Expectancy Value Theory shares some similarities with the SCCT in that competency belief is analogous to self-efficacy and value is analogous to goals and outcome expectations ${ }^{15}$.

\section{Research on Why Students Choose to Study Engineering and Retention in Engineering}

Within the literature, there are multiple studies investigating why students choose to student engineering. In a study on the motivating factors for choosing engineering as reported by racial and ethnic minority students, it was reported that interest was one of the most powerful influences with self-efficacy being the least. Influence from social supports was also high for all groups and influence from outcome expectations was moderate for all groups except among Asian Americans where it was one of the largest influences ${ }^{15}$. Studies at the University of Louisville ${ }^{18}$ and Arizona State University ${ }^{19}$ showed students were also influenced by the belief that engineering jobs would be available and that pay would be good. Other studies have concluded that being good in math and science is a strong motivator to select engineering as a major. ${ }^{20}$

Multiple factors have also been investigated with respect to student retention. Some studies have focused on high school GPA ${ }^{21}$ and standardized test scores ${ }^{9}$. While others have looked at aspect of character like self-control ${ }^{22}$. Still others have looked at demographic and social economic factors such as gender or race ${ }^{3,23-26}$.

Specific studies have investigated the relationship between why a student chose to study engineering and their retention. In a large qualitative study reported in the book Talking about 
leaving by Seymour and Hewitt, the authors discuss choices and preparation of students before entering Science, Mathematics, and Engineering (SME) majors. They interviewed 335 current (at that time) and former science, mathematics and engineering students from seven institutions on their reasons for choosing a major in the SME's originally. Their answers included intrinsic interest, active influence of others, pragmatism and materialism, good at math's and/or science in high school, uninformed choice, means to a desired career end, following family tradition (passive: not pressured), negative choice or compromise, altruism, one of several viable options, recruited and scholarship money available.

From their study, they noted that students who persisted in their original choice of an SME major were more like to have chosen their major due to their interest as compared to students not retained. Students not retained were more likely to have made their choices for reasons not directly related to the nature of the academic work in the majors they chose, such as, the active influence of others, materialistic and pragmatic conditions, and because they were good at math and science from high school ${ }^{27}$. From this work, one realizes that the reasons that students have for pursuing a career in engineering may have a telling effect on whether they are retained or not.

\section{Research Question}

The purpose of this paper is to add to the knowledge base and gain a better understanding of factors related to an individual's probability of graduating and/or persisting in engineering school with respect to the number of reasons they cited for choosing engineering as a field of study. The research questions guiding the study were:

RQ1: Is there a relationship between the number of reasons a student cited they choose engineering as a field of study and the probability of the student being retained after one year? After multiple years?

RQ2: Is there a significant difference in the number of reasons students cited for choosing engineering as a field of study between students who were retained about one year (or multiple years) and those who were not?

\section{Methodology}

Survey data were collated from three cohorts (2010, 2011 and 2012) of first year engineering students attending a large metropolitan research institution during the first week of fall semester as part of a larger study on engineering student performance and retention. No reward or class credit were given for completing the survey, but class time was set aside for the students to complete the survey. The survey consisted of multiple indices and questions related to multiple topics. The current study used responses to the following question:

"Why did you choose Engineering as a major? Check all that apply." The students were given eight possible answers and were at liberty to check as many as applied to them. Table 1 shows the available reasons and the relationship of this reason to the Social Cognitive Theory or the Expectancy-Value Theory. 
Table 1. Available Reasons for Majoring in Engineering and Relationship to Framing Theories

\begin{tabular}{lll}
\hline Reasons & Social Cognitive Theory & Expectancy-Value theory \\
\hline Parent(s) recommended it & Social Support & \\
$\begin{array}{l}\text { Others (teachers, friends etc.) } \\
\text { recommended it }\end{array}$ & Social Support & \\
$\begin{array}{l}\text { Heard engineering provides } \\
\text { good job opportunities }\end{array}$ & Outcome Expectation & Value \\
$\begin{array}{l}\text { Know an engineer } \\
\begin{array}{l}\text { Researched what engineers do } \\
\text { and think I'd like doing that }\end{array}\end{array}$ & Intrinsic Interest & Value \\
$\begin{array}{l}\text { Good at Math and Science } \\
\begin{array}{l}\text { Thought it will help me get into } \\
\text { medical school or graduate } \\
\text { school (other than engineering) }\end{array}\end{array}$ & Self-Efficacy & Expectancy \\
\hline
\end{tabular}

Performance and retention data were extracted from student records and supplied by Institutional Research. The data included the student's academic unit in fall of each year and the semester graduated if applicable. The data spanned from the years 2010-2015. The analysis to answer RQ1 led to separate investigation of each cohort. To answer RQ2 regression analysis was done studying all the cohorts together (first-year and third-year retention rates) to improve the power. We also studied their last year in the data set (fifth-year for 2010 cohort and fourth-year for 2011 cohort). Data from a study on retention showed that seventy-five percent of students who drop out of college do it within their first two years ${ }^{26}$. In the analysis, graduation was considered as part of retention provided the student graduated from the engineering program.

\section{Participants}

The participants were all first-year students at a large metropolitan public research university when they completed the survey. They were predominantly Caucasian with no other group representing over 5\% and overwhelmingly traditional students (app. 99\% directly out of high school). The participants were predominantly male ( $80 \%$ average) across the three cohorts. The 2010 cohort had 321 students and 311 completed the survey (97\% response rate). The 2011 cohort had 371 students and 351 completed the survey (95\% response rate) whilst the 2012 cohort had 435 students with 415 completing the survey (95\% response rate). Due to these high response rates, missing data analysis was not required. 


\section{Analysis}

The total number of reasons students selected to answer the survey question was totaled with equal weighting. For analysis to answer RQ1, each cohort was evaluated separately for each year of retention (ex. 1-year retention, 2-year retention...). After performing $F$-test on the data to determine if the standard deviations of the total number of reasons were equal, $t$-tests were performed to determine if there was a statistical difference in the mean number of reasons selected by students who were retained and those who were not.

For the analysis to answer RQ2 data from all three cohorts were combined. Binomial logistic regression was used to determine if the number of reasons a student selected was related to the likelihood of being retained. All variables were considered categorical and the value $=1$ was used as the reference. Analysis was performed in Microsoft Excel 2016. The histograms and $t$-tests were done using the data analysis tool pack. The logistic regression was done using the real statistics tool pack.

\section{Results}

\section{Summary data}

Most students chose within three to five reasons for deciding to study engineering. No student claimed to have all the eight reasons for pursuing engineering. In 2010 the most reported number of reasons was three reasons (26\%). In 2011 the most reported number of reasons was four (28\%) and in 2012 it was five reasons (24\%). Table 2 shows the number of reasons for studying engineering and the percent of students in each cohort who choose that number of reasons.

Table 2. Percentage of Students Selecting Each Number of Reasons

\begin{tabular}{lrrr}
\hline & \multicolumn{3}{l}{ Percentage of Students } \\
\cline { 2 - 4 } $\begin{array}{l}\text { Number } \\
\text { of }\end{array}$ & $\begin{array}{c}2010 \\
\text { Reasons }\end{array}$ & 2011 & $\begin{array}{c}2012 \\
(n=311)\end{array}$ \\
\hline \multicolumn{1}{c}{$\mathbf{1}$} & $20 \%$ & $14 \%$ & $9 \%$ \\
$\mathbf{2}$ & $17 \%$ & $13 \%$ & $9 \%$ \\
$\mathbf{3}$ & $26 \%$ & $26 \%$ & $20 \%$ \\
$\mathbf{4}$ & $17 \%$ & $28 \%$ & $24 \%$ \\
$\mathbf{5}$ & $12 \%$ & $12 \%$ & $24 \%$ \\
$\mathbf{6}$ & $7 \%$ & $6 \%$ & $12 \%$ \\
$\mathbf{7}$ & $1 \%$ & $1 \%$ & $2 \%$ \\
$\mathbf{8}$ & $0 \%$ & $0 \%$ & $0 \%$ \\
\hline
\end{tabular}

Figures 1-3 show the percentage of students who were retained for the first and latest available year for each number of reasons selected. For the 2010 cohort data allowed for a five- 
year retention/ graduation rate. For the 2012 cohort, the data only allowed for a 3-year retention rate.

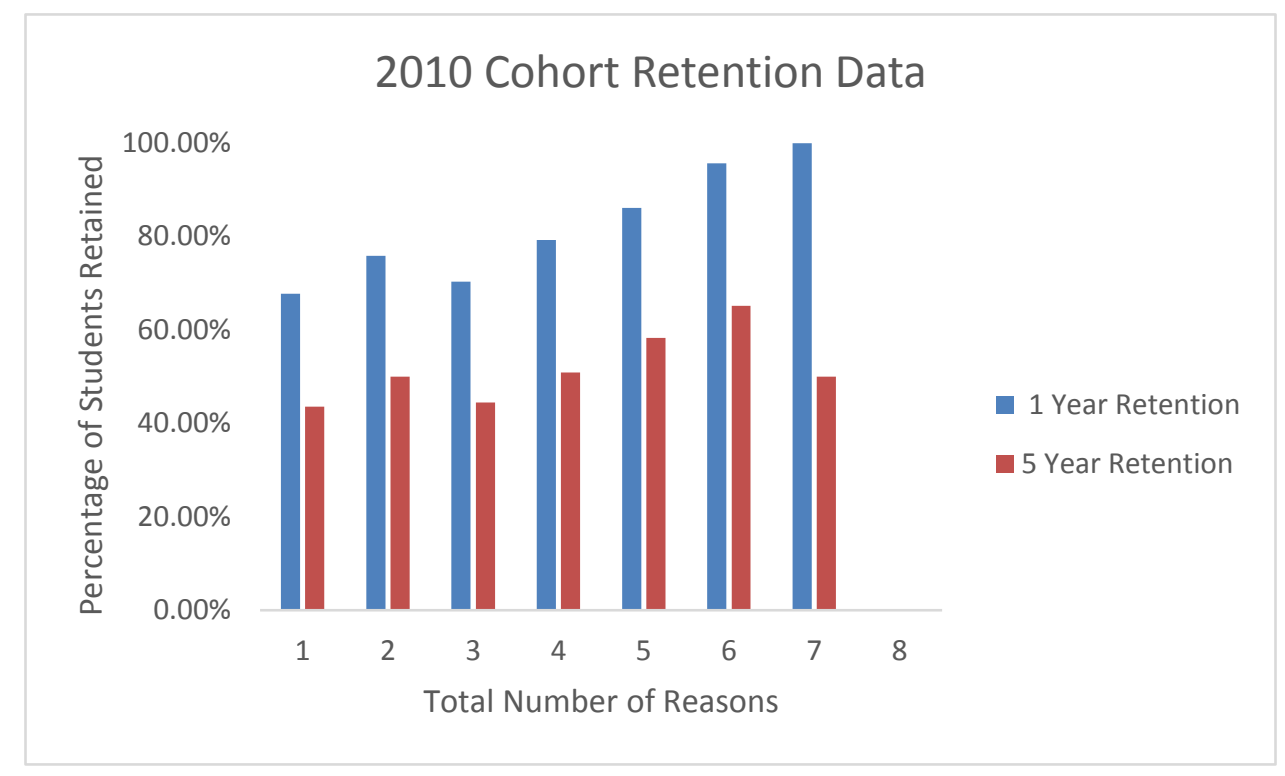

Figure 1. 2010 Cohort- 1 and 5 Year Retention Rate for Number of Reasons Selected

Figure 1 shows the retention in engineering rates for the 2010 cohort after one year and retention/graduation rates after five years. The general trend in the one year retention rate shows that retention rates are higher for students with more reasons for majoring in engineering. Students who selected seven reasons for majoring in engineering had the highest one year retention rate $(100 \%)$ and students who selected one reason had the lowest one year retention rate $(68 \%)$.

The trend was not so clear in the five year retention/graduation. Looking at fifth year retention/graduation, students who chose six reasons had the highest retention rate $(65 \%)$ and students who chose one reason had the lowest retention rate $(44 \%)$.

Table 3. Distribution of Students Who Left between the First Year and the Fifth year for 2010 Cohort

\begin{tabular}{crlrrr}
\hline $\begin{array}{c}\text { Number } \\
\text { of } \\
\text { Reasons }\end{array}$ & $\begin{array}{l}\text { Total } \\
\text { \% } \\
\text { Retained } \\
\text { after } \quad \boldsymbol{1}\end{array}$ & $\begin{array}{r}\text { \% } \\
\text { Rearained } \\
\text { after 5 } \\
\text { years }\end{array}$ & $\begin{array}{r}\text { Difference } \\
\text { Percentages }\end{array}$ & $\begin{array}{r}\text { Number } \\
\text { of }\end{array}$ \\
$\begin{array}{c}\text { Students } \\
\text { lost }\end{array}$ \\
\hline $\mathbf{1}$ & 62 & $68 \%$ & $44 \%$ & $24 \%$ & 15 \\
$\mathbf{2}$ & 54 & $76 \%$ & $50 \%$ & $26 \%$ & 14 \\
$\mathbf{3}$ & 81 & $70 \%$ & $44 \%$ & $26 \%$ & 21 \\
$\mathbf{4}$ & 53 & $79 \%$ & $51 \%$ & $28 \%$ & 15 \\
$\mathbf{5}$ & 36 & $86 \%$ & $58 \%$ & $28 \%$ & 10 \\
$\mathbf{6}$ & 23 & $96 \%$ & $65 \%$ & $30 \%$ & 7 \\
$\mathbf{7}$ & 2 & $100 \%$ & $50 \%$ & $50 \%$ & 1 \\
$\mathbf{8}$ & 0 & $0 \%$ & $0 \%$ & $0 \%$ & 0 \\
\hline
\end{tabular}




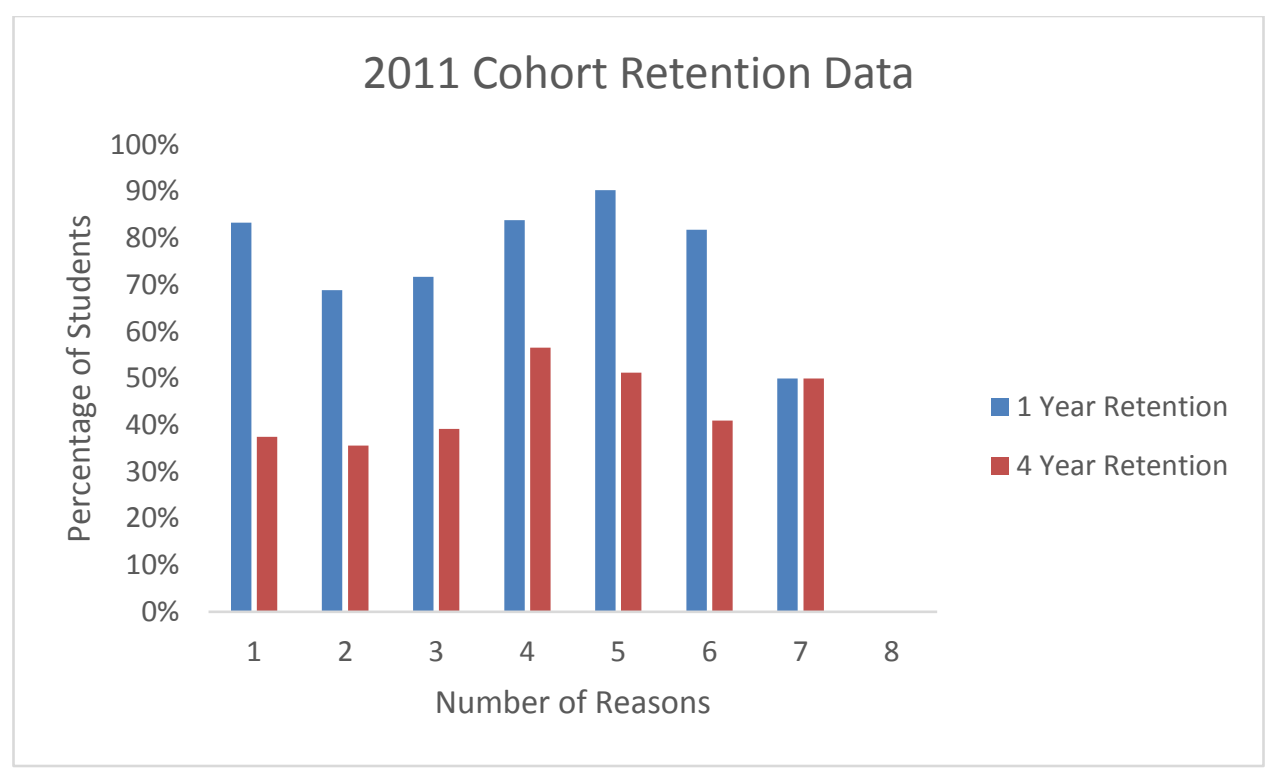

Figure 2. 2011 Cohort- 1 and 4 Year Retention Rate for Number of Reasons Selected

There is a slight difference in the trend with the 2011 cohort in that students with one reason have an abnormally high first-year retention rate. It can also be observed that as the years go on retention rates reduce. This could be due to other contributing factors such as grades. Table 4 shows the sample size for each of the reasons and the percentage of students retained after the first year and the fourth year.

Table 4. Distribution of Students Who Left between the First Year and the Fourth Year for 2011 Cohort

\begin{tabular}{lrrrrr}
\hline $\begin{array}{l}\text { Number } \\
\text { of } \\
\text { Reasons }\end{array}$ & $\begin{array}{l}\text { Total } \\
\text { Number of } \\
\text { Students }\end{array}$ & $\begin{array}{l}\text { \% Retained } \\
\text { after 1 Year }\end{array}$ & $\begin{array}{l}\text { \% Retained } \\
\text { after 4 Years }\end{array}$ & $\begin{array}{l}\text { Difference in } \\
\text { Percentage }\end{array}$ & $\begin{array}{l}\text { Number of } \\
\text { Students } \\
\text { Lost }\end{array}$ \\
\hline $\mathbf{1}$ & 48 & $83 \%$ & $38 \%$ & $46 \%$ & 22 \\
$\mathbf{2}$ & 46 & $69 \%$ & $36 \%$ & $33 \%$ & 15 \\
$\mathbf{3}$ & 93 & $72 \%$ & $39 \%$ & $33 \%$ & 30 \\
$\mathbf{4}$ & 98 & $84 \%$ & $57 \%$ & $27 \%$ & 27 \\
$\mathbf{5}$ & 42 & $90 \%$ & $51 \%$ & $39 \%$ & 16 \\
$\mathbf{6}$ & 22 & $82 \%$ & $41 \%$ & $41 \%$ & 9 \\
$\mathbf{7}$ & 4 & $50 \%$ & $50 \%$ & $0 \%$ & 0 \\
$\mathbf{8}$ & 0 & $0 \%$ & $0 \%$ & $0 \%$ & 0 \\
\hline
\end{tabular}

As can be seen the greatest number of students lost after three years were those who cited between one to four reasons. 


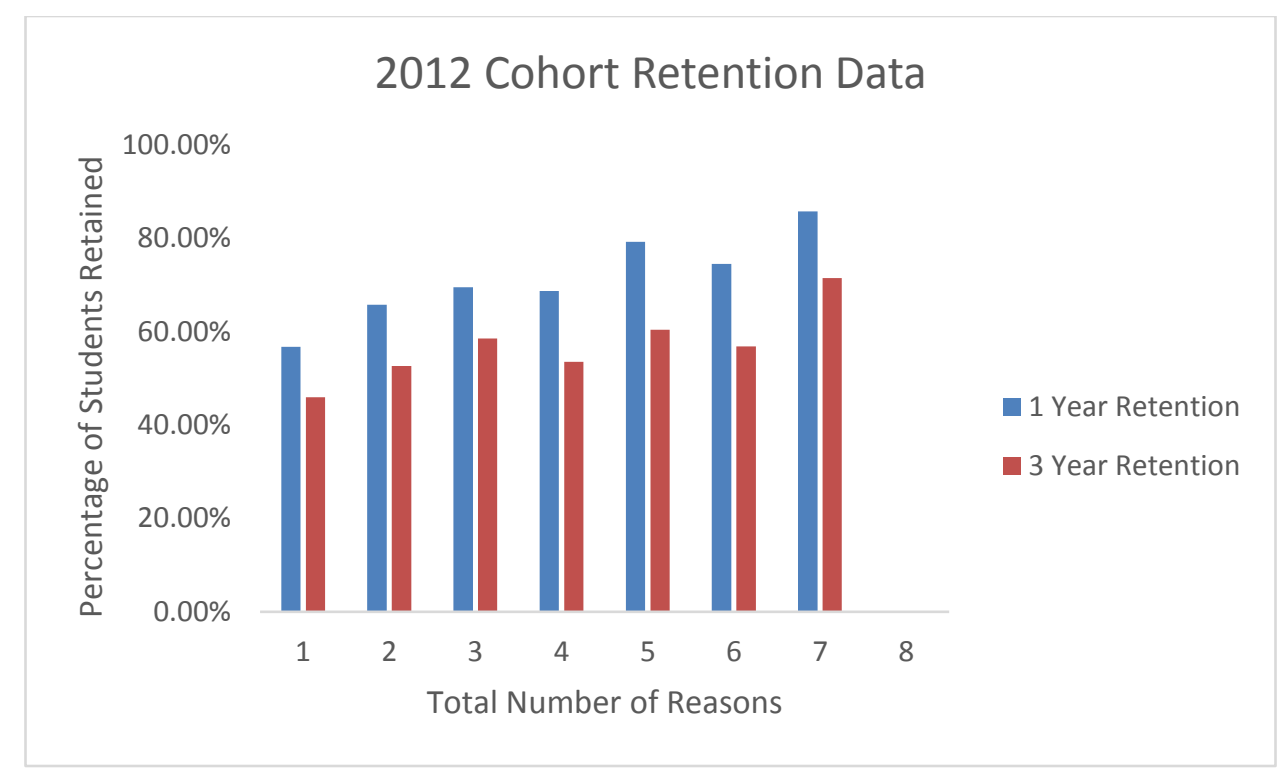

Figure 3. 2012 Cohort- 1 and 3 Year Retention Rate for Number of Reasons Selected

Generally, it can be observed that students were more likely to be retained especially in the first year if they had more reasons for pursuing Engineering. This is especially true for the 2010 and 2012 Cohorts. Also, as can be seen for all year groups most students regardless of the number of reasons they gave were more likely to leave after the first year. Tables 3-5 show a relatively low difference in percentage for students who left between the first year and higher years in school.

Table 5 Distribution of Students Who Left between the First Year and the Third Year for 2012 Cohort

\begin{tabular}{crrrrr}
\hline $\begin{array}{l}\text { Number of } \\
\text { Reasons }\end{array}$ & Total & $\begin{array}{l}\text { \% } \\
\text { Retained } \\
\text { after 1 } \\
\text { Year }\end{array}$ & $\begin{array}{l}\text { \% } \\
\text { Retained } \\
\text { after 3 } \\
\text { Years }\end{array}$ & $\begin{array}{l}\text { lifference } \\
\text { in } \\
\text { Percentages }\end{array}$ & $\begin{array}{l}\text { Number } \\
\text { of } \\
\text { Students } \\
\text { Lost }\end{array}$ \\
\hline $\mathbf{1}$ & 37 & $57 \%$ & $46 \%$ & $11 \%$ & 4 \\
$\mathbf{2}$ & 38 & $66 \%$ & $53 \%$ & $13 \%$ & 5 \\
$\mathbf{3}$ & 82 & $70 \%$ & $59 \%$ & $11 \%$ & 9 \\
$\mathbf{4}$ & 99 & $69 \%$ & $54 \%$ & $15 \%$ & 15 \\
$\mathbf{5}$ & 101 & $79 \%$ & $60 \%$ & $19 \%$ & 19 \\
$\mathbf{6}$ & 51 & $75 \%$ & $57 \%$ & $17 \%$ & 9 \\
$\mathbf{7}$ & 7 & $86 \%$ & $71 \%$ & $15 \%$ & 1 \\
$\mathbf{8}$ & 0 & $0 \%$ & $0 \%$ & $0 \%$ & 0 \\
\hline
\end{tabular}


Data from the 2012 cohort, like those for the previous year's, show that students with a higher number of reasons are more likely to stay than to leave. We also realize the likelihood of staying is greater with a greater number of reasons for studying engineering. Table 5 shows us the sample size for each of the number of reasons reported by students as well as the percentage of students retained after the first year and the third year.

\section{Results for RQ1}

Table 6 displays the results from the $t$-test analysis to determine if there was a significant difference in the number of reasons chosen to study engineering between the students who were retained in engineering and those who left engineering. There was a significant difference in the mean number of reasons selected for the students who were and were not retained after one year in the 2010 and 2012 cohorts, but not for the 2011 cohort. In all scenarios students retained had a higher mean number of reasons for pursuing engineering.

Table 6. $t$-test Values for the Various Cohorts

\begin{tabular}{lcccc}
\hline & \multicolumn{4}{l}{$\begin{array}{l}\text { Mean Number of } \\
\text { Reasons Give for } \\
\text { Choosing Engineering }\end{array}$} \\
& Retained & Not Retained & $t$ (df) & $p$ \\
\hline $\mathbf{2 0 1 0}$ (1-year retention) & 3.22 & 2.61 & $-3.38(148)$ & $<.001$ \\
$\mathbf{2 0 1 0}$ (5-year retention) & 3.24 & 2.92 & $-1.86(309)$ & 0.032 \\
$\mathbf{2 0 1 1}$ (1-year retention) & 3.39 & 3.17 & $-1.17(351)$ & 0.121 \\
$\mathbf{2 0 1 1}$ (4-year retention) & 3.62 & 2.92 & $-4.61(351)$ & $<.001$ \\
$\mathbf{2 0 1 2}$ (1-year retention) & 4.01 & 3.59 & $-2.62(413)$ & 0.004 \\
$\mathbf{2 0 1 2}$ (3-year retention) & 3.98 & 3.78 & $-1.34(413)$ & 0.090 \\
\hline
\end{tabular}




\section{Results for $R Q^{2}$}

The results from the logistic regression are presented in Table 7. Data from the three cohorts were combined to investigate if the number of reasons chosen was related to the likelihood a student would be retained in engineering for 1 or 3 years. Since 4 and 5 year retention data was only available for the 2010 and 2011 cohorts respectively, data from just one cohort was used in the 4 and 5 year retention analysis. The results show that the likelihood of a student being retained for one, three or four years increases with each reason a student indicated they choose engineering. Based on the odds ratio, for every additional reason a student selected, their likelihood of being retained 1 year increase by $17 \%$ and the increase was $22 \%$ for being retained 2 years.

The sample size for the 4 and 5 year retention/graduation analysis were much smaller. This might explain why the number of reasons selected was not a significant predictor of the probability of being retained/graduated after 5 years.

Table 7. Logistic Regression Results

\section{5\% Confidence} Interval

\begin{tabular}{|c|c|c|c|c|c|c|}
\hline Cohort & s.e. & Wald & $p$-value & Odds Ratio & lower & upper \\
\hline 2010 (5-year retention) & 0.075 & 3.400 & 0.065 & 1.147 & 0.991 & 1.328 \\
\hline 2011 (4-year retention) & 0.082 & 19.223 & $<.001$ & 1.434 & 1.221 & 1.686 \\
\hline 1 Year Retention All Cohorts & 0.047 & 11.057 & 0.001 & 1.169 & 1.066 & 1.281 \\
\hline 3 Year Retention All Cohorts & 0.042 & 22.370 & $<.001$ & 1.217 & 1.122 & 1.321 \\
\hline
\end{tabular}




\section{Conclusion}

Analysis in this study showed that students with a greater number of reasons for pursuing engineering were more likely to be retained as compared to students with fewer reasons, especially with regards to first year retention. These results are consistent with the Expectancy Value Theory and the Social Cognitive Theory. Both theories predict persistence if multiple conditions exist. The reasons in this study given for deciding to study engineering correspond to conditions of these theories. For example, one would not be expected to persist in engineering if he/she saw no value in getting the degree or they did not think they could be successful. Thus if students only picked one of these reasons to study engineering, they would not be expected to persist based on the Expectancy Value Theory. There were multiple reasons available for students to choose related to value such as "heard engineering provides good job opportunities", "Researched what engineers do and think I will like doing it" and "thought it will get me into medical school or graduate school (other than engineering)-, the more reasons chosen the more value the students places in obtaining an engineering degree and based on the Expectancy value theory the more likely the student would be retained.

Per the Social Cognitive Theory, the student more likely to persist will have reasons that impress self-efficacy beliefs, intrinsic interest, outcome expectation and social support. The student would therefore have multiple reasons to cover these components of this theory. A student therefore with these reasons is more likely to succeed.

This study was taken in the first week of the first year in the students' program, it is therefore understandable that some students as the years go by will have different reasons or may change their reasons.

Retention of students in engineering is important for multiple reasons. Retention therefore needs to be tackled even before students begin the college experience. High school counsellors and teachers need to spend time explaining to students what engineering really entails. Colleges and engineers may also need to increase their outreach to high schools to introduce more students to engineering and answer any possible questions they may have. 


\section{REFERENCES}

1. Sirak, M. C. Game changers. Air Force Mag. 92, 30-38 (2009).

2. Performance-Based Funding for Higher Education. Available at: http://www.ncsl.org/research/education/performance-funding.aspx. (Accessed: 5th February 2017)

3. Kena, G. et al. The Condition of Education - 2016. U.S. Dep. Educ. Natl. Cent. Educ. Stat. 4-29 (2016). doi:10.1037/e492172006-019

4. Cominole, M. \& Paslov, J. Trends in Undergraduate Nonfederal Grant and Scholarship Aid by Demographic and Enrollment Characteristics, Selected Years: 1999-2000 to 2011-12. 40 (1999).

5. Woo, J. H. \& Shaw, S. Trends in Graduae Student Financing: Selected Years, 1995-96 to 2011-12. (2015).

6. US Congress Joint Economic Committee. STEM Education: Preparing for the Jobs of the Future. Washingt. DC (2012).

7. Charrette, R. The STEM Crisis Is a Myth. IEEE Spectr. 50, 45-59 (2013).

8. Johnson, M. M. \& Molnar, D. Comparing Retention Factors for Anglo, Black, and Hispanic Students. (1996).

9. Ford, G. D., Steffen, R. E. \& Ford, R. W. University Freshman Retention in North Carolina. 2012 Asee Annu. Conf. (2012).

10. Peuker, S. \& Schauss, N. A. G. Improving student success and retention rates in engineering: An innovative approach for first-year courses. ASEE Annu. Conf. Expo. Conf. Proc. 122nd ASEE, (2015).

11. Moller-Wong, C., Arvid \& Eide. An engineering student retention study. J. Eng. Educ. 86, 7-15 (1997).

12. Hall, C. W. et al. Aptitude and personality traits in retention of engineering students. $J$. Eng. Educ. 104, 167-188 (2015).

13. Hermond, D. Measuring the retention strategies of a minority engineering program: A service quality perspective. J. Eng 84, 395-400 (1995).

14. Social Cognitive Career Theory - Career Development - IResearchNet. Available at: http://career.iresearchnet.com/career-development/social-cognitive-career-theory/. (Accessed: 2nd February 2017)

15. Id, P. et al. Motivating Factors for Choosing Engineering as Reported by Racial and Ethnic Minority Students Fundamental : Motivating Factors for Choosing Engineering among Minority Students. (2015).

16. Lent, R. W., Lopez, F. G., Sheu, H. Bin \& Lopez, A. M. Social cognitive predictors of the 
interests and choices of computing majors: Applicability to underrepresented students. $J$. Vocat. Behav. 78, 184-192 (2011).

17. Expectancy Value Theory. Available at:

https://www.utwente.nl/cw/theorieenoverzicht/Theory Clusters/Public Relations, Advertising, Marketing and Consumer Behavior/Expectancy_Value_Theory/. (Accessed: 2nd February 2017)

18. Honken, N. \& Ralston, P. A. S. Freshman Engineering Retention: A Holistic Look. J. STEM Educ. Innov. Res. 14, 29-37 (2013).

19. Anderson-rowland, M. R. Motivated Engineering Transfer Students / STEP after Six Years Motivated Engineering Transfer Students / STEP after Six Years Abstract. (2015).

20. Mcllwee, J. \& Robinson, G. Women in Engineering: Gender, Power and Workplace Culture. (State University of New York Press, 1992).

21. Hall, C., Urquidi, K. De \& Wuensch, K. Longitudinal study of entering students with engineering as their major: Retention and academic success. Age (Omaha). (2013).

22. Honken, N. \& Ralston, P. A. High School Homework Habits and Success in First year Engineering. 122nd ASEE Annu. Conf. Expo. (2015). doi:10.18260/p.24182

23. Mondisa, J. \& Lafayette, W. Mentoring Minorities : Examining Mentoring from a Race and Gender Lens Mentoring Minorities : Examining Mentoring from a Race and Gender Lens. (2014).

24. Orr, M. K., Ramirez, N. M. \& Ohland, M. Socioeconomic Trends in Engineering : Enrollment, Persistence, and Academic Achievement. Am. Soc. Eng. Educ. (2011).

25. Astin, A. W. How 'good' is your institution's retention rate? Res. High. Educ. 38, 647658 (1997).

26. Christopher, B. \& Mattson, E. Beyond Admission : J. Coll. Admissions (2007).

27. Seymour, E. \& Hewitt, N. Talking About Leaving. (Westview Press, HarperCollins Publishers, 1997). 